\title{
Operative and nonoperative management for renal trauma: comparison of outcomes. A systematic review and meta-analysis
}

This article was published in the following Dove Press journal:

Therapeutics and Clinical Risk Management

3I August 2017

Number of times this article has been viewed

\author{
Andrea Mingoli, ${ }^{1,2}$ \\ Marco La Torre ${ }^{1,2}$ \\ Emanuele Migliori, ${ }^{1,2}$ \\ Bruno Cirillo ${ }^{1,2}$ \\ Martina Zambon ${ }^{1,2}$ \\ Paolo Sapienza ${ }^{1,2}$ \\ Gioia Brachini ${ }^{1,2}$ \\ 'Emergency Department, ${ }^{2}$ Department \\ of Surgery P Valdoni, Policlinico \\ Umberto I, Sapienza University, Rome, \\ Italy
}

Introduction: Preservation of kidney and renal function is the goal of nonoperative management (NOM) of renal trauma (RT). The advantages of NOM for minor blunt RT have already been clearly described, but its value for major blunt and penetrating RT is still under debate. We present a systematic review and meta-analysis on NOM for RT, which was compared with the operative management $(\mathrm{OM})$ with respect to mortality, morbidity, and length of hospital stay (LOS).

Methods: The Preferred Reporting Items for Systematic Reviews and Meta-analyses statement was followed for this study. A systematic search was performed on Embase, Medline, Cochrane, and PubMed for studies published up to December 2015, without language restrictions, which compared NOM versus OM for renal injuries.

Results: Twenty nonrandomized retrospective cohort studies comprising 13,824 patients with blunt $(2,998)$ or penetrating $(10,826)$ RT were identified. When all RT were considered (American Association for the Surgery of Trauma grades 1-5), NOM was associated with lower mortality and morbidity rates compared to OM ( $8.3 \%$ vs $17.1 \%$, odds ratio [OR] 0.471 ; $95 \%$ confidence interval [CI] $0.404-0.548 ; P<0.001$ and $2 \%$ vs $53.3 \%$, OR $0.0484 ; 95 \%$ CI $0.0279-0.0839, P<0.001)$. Likewise, NOM represented the gold standard treatment resulting in a lower mortality rate compared to $\mathrm{OM}$ even when only high-grade RT was considered (9.1\% vs $17.9 \%$, OR $0.332 ; 95 \%$ CI $0.155-0.708 ; P=0.004)$, be they blunt $(4.1 \%$ vs $8.1 \%$, OR $0.275 ; 95 \%$ CI $0.0957-0.788 ; P=0.016)$ or penetrating $(9.1 \%$ vs $18.1 \%$, OR $0.468 ; 95 \%$ CI 0.398-0.0552; $P<0.001)$.

Conclusion: Our meta-analysis demonstrated that NOM for RT is the treatment of choice not only for AAST grades 1 and 2, but also for higher grade blunt and penetrating RT.

Keywords: renal trauma, blunt trauma, penetrating trauma, operative management, nonoperative management, systematic review, meta-analysis

\section{Introduction}

The kidney is the third most frequently injured organ in abdominal trauma after the spleen and liver. ${ }^{1}$ In the last 30 years, the treatment strategy of renal trauma has changed from operative management (OM) to nonoperative management (NOM). ${ }^{1}$ Several studies showed improving outcomes when NOM was applied in blunt trauma and, therefore, conservative management gained an increasing popularity among trauma surgeons. ${ }^{2-4}$

However, specific guidelines regarding renal trauma are still lacking and the few papers providing recommendations are not supported by relevant grades of evidence.
Correspondence: Andrea Mingoli Department of Surgery P Valdoni, Sapienza University, Policlinico Umberto I, Viale del Policlinico I55, 00161, Rome, Italy

Email andrea.mingoli@uniromal.it 
Immediate surgical management of injuries with lifethreatening hemorrhage is widely accepted; however, when this clear-cut indication is lacking, several differences in management strategies emerge from the literature..$^{5-8}$ A successful conservative management for blunt low-grade renal injury (renal contusions and minor lacerations) is well documented with a low complication rate, ${ }^{9,10}$ but what about the optimal management of penetrating and high-grade blunt injuries?

We first investigated through a systematic review and meta-analysis the efficacy of OM and NOM on any grade, blunt or penetrating, renal trauma and evaluated mortality, morbidity, and length of hospital stay (LOS) for the different types of injuries and management.

\section{Methods}

\section{Study selection}

The criteria of the "Preferred Reporting Items for Systematic Reviews and Meta-analyses (PRISMA) statement" were followed in the present study. ${ }^{11}$ Embase, Medline, Cochrane, and PubMed databases were used to identify studies, published up to December 2015, comparing blunt and penetrating renal trauma in adults. The following MESH search headings were used: "operative and non-operative management renal trauma", "operative and non-operative treatment for blunt and penetrating adult renal injury", "operative and non-operative treatment for genitourinary trauma", and "operative and non-operative management kidney injury". The "related articles" function in PubMed database was used to increase and widen the search to all similar abstracts and studies.

\section{Inclusion criteria}

Studies comparing the selected clinical outcomes - that is, mortality, morbidity and length of stay - of adult patients submitted to OM and NOM for renal trauma were selected for the analysis.

\section{Exclusion criteria}

We did not consider for meta-analysis: 1) studies in which mortality, morbidity, and LOS were not reported separately for NOM and OM, 2) studies analyzing pediatric patients, or 3) papers reporting series already selected for this metaanalysis.

\section{Data extraction}

Data concerning study author, year of publication, patient characteristics, study design, number of patients submitted to NOM or OM, mortality rates, morbidity rates, and length of stay (LOS) were extracted and inserted into a database.

\section{Outcomes of interest and definition}

Patients' demographics (age and sex), trauma characteristics (open or blunt), trauma severity (Injury Severity Score - ISS), American Association for the Surgery of Trauma (AAST) grade, hemodynamic stability, type of management (operative and nonoperative), and clinical outcomes (morbidity, mortality, LOS) were retrieved.

Morbidity and mortality were defined as in-hospital complication and mortality rates.

Intervention types were defined as: NOM (clinical observation, medical treatment, and proximal or distal renal angio-embolization) and OM (total or partial nephrectomy, nephrorrhaphy, or application of hemostatic agents).

\section{Study endpoints}

The primary endpoint was the overall mortality and morbidity defined as any death or complication that occurred after the start of NOM or OM and during the hospital stay for all renal trauma (blunt and penetrating).

The secondary endpoint was the overall mortality and morbidity that occurred after the start of NOM or OM and during the hospital stay for blunt and penetrating renal trauma considered separately.

The tertiary endpoint was the overall mortality and morbidity that occurred after the start of NOM or OM and during the hospital stay for all high-grade renal trauma (AAST 3-5).

The quaternary endpoint was the length of stay after the start of NOM or OM.

\section{Study selection}

A total of 465 papers were identified at the end of the literature search. After a first evaluation performed by abstract analysis, 369 studies were excluded because they were irrelevant to the purpose of our study, and 37 studies because of overlapping data. The full-text analysis of the 49 remaining studies resulted in exclusion of 29 because they did not match the inclusion criteria, while 20 were selected for further analysis. ${ }^{5,12-30}$

\section{Search strategy results}

Twenty nonrandomized retrospective cohort studies (Table 1) accounting for a total of 13,824 patients affected with renal injury form the basis of our analysis; 11,426 patients underwent NOM and 2,398 OM.

\section{Quality of included studies}

The quality of included studies was assessed by two authors (MLT and AM) using the Newcastle-Ottawa Scale (NOS). ${ }^{31}$ 
Table I Study selection

\begin{tabular}{|c|c|c|}
\hline Reference & Type of study & Patients (N) \\
\hline McGuire et $\mathrm{al}^{5}$ & Retrospective & 117 \\
\hline Sugihara et $\mathrm{al}^{12}$ & Retrospective & 1,505 \\
\hline Yang et $\mathrm{al}^{13}$ & Retrospective & 73 \\
\hline Sahin et $\mathrm{al}^{14}$ & Retrospective & 135 \\
\hline Hammer and Santucci ${ }^{15}$ & Retrospective & 51 \\
\hline Buckley and McAninch ${ }^{16}$ & Retrospective & 43 \\
\hline Kansas et $\mathrm{al}^{17}$ & Retrospective & 206 \\
\hline Moolman et al ${ }^{18}$ & Retrospective & 92 \\
\hline McClung et $\mathrm{al}^{19}$ & Retrospective & 9,584 \\
\hline Aragona et $\mathrm{al}^{20}$ & Retrospective & 45 \\
\hline van der Vlies et $\mathrm{a}^{21}$ & Retrospective & 186 \\
\hline Gourgiotis et $\mathrm{al}^{22}$ & Retrospective & 28 \\
\hline Starnes et $\mathrm{a}^{23}$ & Retrospective & 889 \\
\hline Bjurlin et $\mathrm{al}^{24}$ & Retrospective & 97 \\
\hline Shariat et $\mathrm{a}^{25}$ & Retrospective & 77 \\
\hline Menaker et $\mathrm{al}^{26}$ & Retrospective & 434 \\
\hline Raheem et $\mathrm{al}^{27}$ & Retrospective & 25 \\
\hline Sangthong et $\mathrm{a}^{28}$ & Retrospective & 517 \\
\hline Shoobridge et al ${ }^{29}$ & Retrospective & 338 \\
\hline Bozeman et $\mathrm{a}^{30}$ & Retrospective & 26 \\
\hline
\end{tabular}

All included studies had good methodological quality ( $>5$ points; mean 6.9 points, range $6-9$ ).

\section{Risk of bias}

Distribution of age, sex, and ISS were homogenous between the NOM and OM groups. Conversely, the AAST grade was not homogenous between the two groups: in the NOM group, there were 3,252 (28.5\%) high-grade (AAST 3-5) renal trauma whereas in the OM group they were 1,387 $(57.8 \% ; P<0.0001)$.

\section{Statistical analysis}

Statistical analysis was conducted using MedCalc for Windows, version 10.2.0.0 (MedCalc Software, MariaKerke, Belgium).

Odds ratio (OR), for dichotomous outcomes, was calculated by the Mantel-Haenszel method, while standardized mean difference (SMD), for continuous outcomes, was calculated by Hedges $g$ statistic. Results from the meta-analysis for OR were considered statistically significant $(P<0.05)$ if the value 1 was not within the $95 \% \mathrm{CI}$, whereas for SMD, it was if the value 0 was not within the $95 \%$ CI.

Heterogeneity was also studied by calculating the $\mathrm{Chi}^{2}$ and the inconsistency $\left(I^{2}\right)$. As $I^{2}$ detected the absence of homogeneity $(>50 \%)$, the fixed effect model could not be used; therefore, the random effect model was used for analysis.

If the test of heterogeneity was statistically significant $(P<0.05)$, then more emphasis should be placed on the random effects model.

\section{Results}

Twenty retrospective cohort studies comprising 13,824 patients were selected (Table 1). Eight studies analyzed 2,998 patients with blunt renal trauma (BRT), ${ }^{5,12,23,26-30}$ whereas 12 studies analyzed the remaining 10,826 patients with penetrating renal trauma (PRT). ${ }^{14-24,28}$ Patient characteristics are summarized in Table 2.

NOM was the most frequent and prevalent strategy adopted for renal trauma, with $11,426(82.4 \%)$ patients treated conservatively versus $2,398(17.3 \%)$ patients treated operatively (Table 3).

NOM was significantly more frequently adopted in BRT, compared to PRT (Table 3; $P<0.0001$ ). Table 4 shows the distribution of NOM and OM according to the severity of renal trauma (AAST scale), both for penetrating or blunt trauma. A significantly higher number of patients was treated conservatively for low-grade trauma and a significantly higher number of patients was treated operatively for highgrade trauma $(P<0.0001)$.

Further analysis pursued the following criteria: 1) An analysis concerning all renal trauma (AAST low and high grades) and 2) an analysis concerning only high-grade renal trauma.

\section{NOM versus OM for all renal trauma}

Eleven studies compared morbidity, 5,12,15,18,22-25,27,29,30 twelve compared mortality, ${ }^{12,13,15,17-19,22,26-30}$ and four compared LOS, $19,26,28,30$ according to OM and NOM.

A higher mortality rate for OM $(17.1 \%, 274 / 1,598)$ compared to NOM $(8.3 \% 887 / 10,642$; OR $0.471 ; 95 \%$

Table 2 Patient characteristics

\begin{tabular}{ll}
\hline Characteristics & $\mathbf{N}=\mathbf{I 3 , 8 2 4}$ \\
\hline Mean age (years) & 32.7 \\
NOM & 31.9 \\
OM & 32.15 \\
Type of trauma (\%) & \\
$\quad$ Blunt & $2,998(21.7)$ \\
Penetrating & $10,826(78.3)$ \\
NOM (\%) & $11,426(82.7)$ \\
OM (\%) & $2,398(17.3)$ \\
High-grade renal trauma (\%) (AAST 3-5) & $11,271(81.5)$ \\
Low-grade renal trauma (\%) (AAST I-2) & $2,553(18.5)$ \\
Mean ISS & 23.4 \\
NOM & 21.7 \\
OM & 25.7 \\
Mean overall morbidity (\%) & 32.7 \\
Mean overall mortality (\%) & 13.5 \\
Mean overall LOS (days) & 12.5 \\
\hline Abbrevations: NOM, nop
\end{tabular}

Abbreviations: NOM, nonoperative management; OM, operative management; AAST, American Association for the Surgery of Trauma; ISS, injury severity score; LOS, length of stay. 
Table 3 Chi-square test analyzing the proportion of patients treated with NOM and OM

\begin{tabular}{llll}
\hline & NOM & OM & P-value \\
\hline Penetrating trauma & $8,653(75.7 \%)$ & $2,173(90.6 \%)$ & $<0.000$ I \\
Blunt trauma & $2,773(24.3 \%)$ & $225(9.4 \%)$ & \\
Total & $11,426(82.7 \%)$ & $2,398(17.3 \%)$ & \\
\hline
\end{tabular}

Abbreviations: NOM, nonoperative management; OM, operative management.

CI 0.404-0.548; $P<0.001)$ was observed when all renal trauma were considered (Figure 1).

No statistical differences were encountered in terms of morbidity and LOS (OR 0.490; 95\% CI 0.0775-3.101; $P=0.449$ and $\mathrm{SMD}=0.0407 ; 95 \% \mathrm{CI}-0.017$ to 0.099 ; $P=0.171$; Figures 2 and 3 ).

\section{NOM versus OM for all-grade BRT}

Five studies compared morbidity,,$^{5,12,27,29,30}$ seven compared mortality, ${ }^{12,13,26-30}$ and three compared LOS. ${ }^{26,28,30}$

We observed significantly higher morbidity and mortality rates with OM versus NOM when only blunt trauma were studied (the analysis included all grades of renal trauma according to the AAST scale; Figures 4 and 5).

After NOM, we observed a lower morbidity rate $(38 / 1,869,2 \%)$ when compared to $\mathrm{OM}(56 / 105,53.3 \%)$ (OR 0.0484; 95\% CI 0.0279-0.0839; P<0.001) as well as a lower mortality rate $(130 / 2,676,4.8 \%$, vs $33 / 205,16.1 \%$; OR 0.445 ; $95 \%$ CI $0.0528-0.942 ; P=0.041)$.

LOS was similar between OM and NOM (SMD -0.326; $95 \% \mathrm{CI}-0.802$ to $0.150 ; P=0.180$; Figure 6 ).

\section{NOM versus OM for all-grade PRT}

Six studies compared morbidity, ${ }^{15,18,22-25}$ and five compared mortality. ${ }^{15,17-19,23}$ No studies specifically analyzed LOS.

A significantly lower mortality rate of $\operatorname{NOM}(757 / 7,966$, 9.5\%) when compared to OM (241/1,393, $13.3 \%$; OR 0.459; 95\% CI $0.390-0.540 ; P<0.001)$ was recorded for all penetrating trauma (Figure 7).

Morbidity was similar for OM and NOM (OR 1.565; 95\% CI 0.422-5.802; $P=0.503$; Figure 8).

Table 4 Chi-square test analyzing the proportion of patients treated with NOM and OM according to AAST scale

\begin{tabular}{|c|c|c|c|c|c|c|}
\hline & \multicolumn{5}{|c|}{ AAST scale } & \multirow[t]{2}{*}{$P$-value } \\
\hline & AAST I & AAST 2 & AAST 3 & AAST 4 & AAST 5 & \\
\hline \multicolumn{7}{|c|}{ Penetrating trauma } \\
\hline NOM & 2,652 & 2,680 & 1,653 & 1,013 & 219 & $<0.0001$ \\
\hline OM & 52 & 178 & 342 & 540 & 430 & \\
\hline \multicolumn{7}{|c|}{ Blunt trauma } \\
\hline NOM & 121 & 311 & 125 & 211 & 31 & $<0.0001$ \\
\hline OM & 0 & 2 & 8 & 17 & 50 & \\
\hline
\end{tabular}

Abbreviations: AAST, American Association for the Surgery of Trauma; NOM, nonoperative management; OM, operative management.

\section{NOM versus OM for high-grade (3-5)} renal trauma

Seven studies compared morbidity, ${ }^{15,22-25,29,30}$ seven compared mortality, ${ }^{13,15,19,22,26,29,30}$ and three compared LOS. ${ }^{19,26,30}$

When all high-grade BRT or PRT were considered, a higher mortality rate for OM $(17.9 \%, 790 / 8,658)$, when compared to $\operatorname{NOM}(9.1 \%, 229 / 1,276$; OR $0.332 ; 95 \%$ CI $0.155-0.708 ; P=0.004$; Figure 9 ), and a reduced LOS (SMD $0.0905,95 \%$ CI $0.030-0.151, P=0.003)$ were recorded (Figure 10).

No statistical differences were observed in terms of morbidity (OR $0.733,95 \%$ CI $0.125-4.285, P=0.730$; Figure 11).

\section{NOM versus OM for high-grade BRT}

Two studies compared morbidity, ${ }^{29,30}$ four compared mortality, ${ }^{13,26,29,30}$ and two compared LOS. ${ }^{26,30}$

A significantly higher mortality rate for OM versus NOM (4.1\%,33/791 vs $8.1 \%, 5 / 62$; OR $0.275 ; 95 \%$ CI $0.0957-0.788$; $P=0.016$ ) was recorded (Figure 12).

Morbidity and LOS were similar between OM and NOM (OR 0.123; 95\% CI 0.0002-73.434; $P=0.521$ and SMD $-0.0880 ; 95 \%$ CI -0.594 to $0.418 ; P=0.733$, respectively; Figures 13 and 14).

\section{NOM versus OM for high-grade PRT}

Six studies compared morbidity, ${ }^{15,18,22-25}$ and four compared mortality. ${ }^{15,18,19,22}$ No studies specifically analyzed LOS.

A significantly higher mortality rate of OM versus NOM (9.1\%, 757/7,914 vs $18.1 \%, 224 / 1,239$; OR $0.468 ; 95 \%$ CI $0.398-0.552 ; P<0.001$ ) was observed (Figure 15).

No statistical differences were observed in terms of morbidity (OR 1.565; 95\% CI 0.422-5.802; $P=0.503$ ) between the two groups (Figure 16).

\section{Discussion}

The kidney is the third most commonly injured solid organ after blunt trauma, and the second most commonly affected after penetrating trauma. ${ }^{1}$ Every year, 245,000 renal trauma cases occur worldwide, with blunt trauma representing approximately $80 \%$ of cases. ${ }^{1}$

The treatment strategy of BRT has not changed in the last 30 years. The standard of care is, in most cases, nonoperative and up to $95 \%$ of the pediatric patients do not undergo surgery. ${ }^{1-4,9}$ Conversely, the management of penetrating injuries has significantly changed. ${ }^{29,30}$ Traditionally, penetrating renal injuries were managed with exploration, nephrorrhaphy, partial nephrectomy, or nephrectomy. ${ }^{17,18}$ 


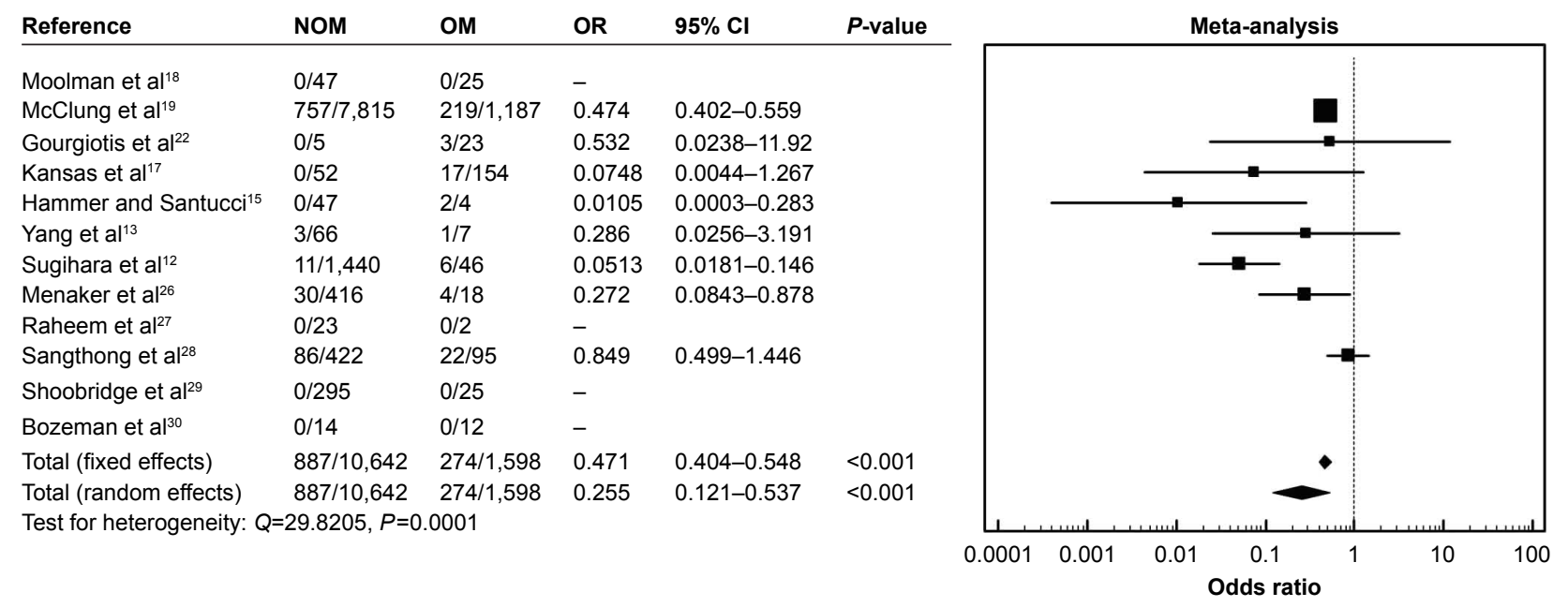

Figure I Overall mortality.

Note: The OR was not calculated when the results at the univariate analysis were not statistically significant: this is represented with "-" and consequently there is no $95 \% \mathrm{Cl}$. Abbreviations: $\mathrm{Cl}$, confidence interval; NOM, nonoperative management; OM, operative management; OR, odds ratio.

The approach to renal gunshot wounds was still more prudent and careful, with surgical exploration and repair considered mandatory treatment. In 1997, Wessells et al suggested that many grade 2 penetrating renal injuries can be managed nonoperatively. ${ }^{32}$ In 1998, Velmahos et al reported that a kidney exploration was not necessary in approximately $40 \%$ of renal gunshot trauma. ${ }^{33}$ In 2006, the same authors showed that a nonoperative management was successful in $50 \%$ of isolated penetrating kidney injuries. ${ }^{34}$

In our meta-analysis, we demonstrated that NOM was the most frequent and prevalent strategy of cure used for renal trauma in adults, with $11,426(82.4 \%)$ patients conservatively treated $(17.3 \%)$ versus 2,398 patients who underwent surgery. However, when we analyzed the distribution of NOM and OM on the basis of the severity of renal trauma (AAST scale), we observed a significantly higher number of patients with low-grade trauma treated conservatively and a significantly higher number of patients with highgrade trauma treated operatively $(P<0.0001)$. Furthermore, NOM was more frequently used in BRT, compared to PRT $(P<0.0001)$.

Major debate concerns the indications for surgical exploration - both for BRT and PRT in high-grade trauma. The experience translated from NOM in pediatric hepatic and splenic trauma, the availability of multi-slice computerized tomography, and the acquisition of angiographic embolization techniques demonstrated that, NOM in selected hepatic and splenic high-grade trauma, also in adults, has better outcomes in terms of morbidity, mortality, and LOS when compared to surgical exploration. ${ }^{34-37}$ In the present study, we clearly demonstrated that NOM can be safely performed even for high-grade RT, allowing a significant reduction

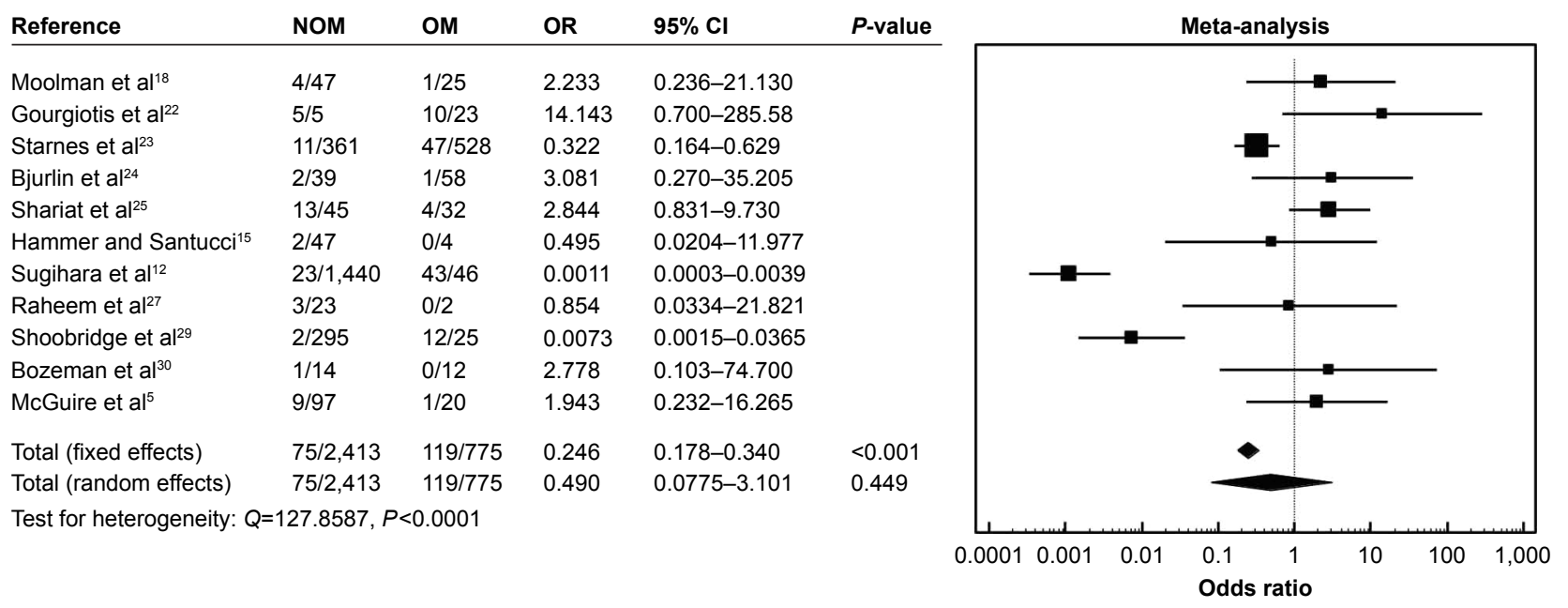

Figure 2 Overall morbidity.

Abbreviations: $\mathrm{Cl}$, confidence interval; NOM, nonoperative management; OM, operative management; OR, odds ratio. 


\begin{tabular}{lcccccc} 
Reference & NOM & OM & Total & SMD & 95\% Cl & $P$-value \\
\hline McClung et al ${ }^{19}$ & 7,815 & 1,187 & 9,002 & 0.0955 & $0.034-0.157$ & \\
Menaker et al ${ }^{26}$ & 416 & 18 & 434 & -0.276 & $-0.749-0.196$ & \\
Sangthong et al ${ }^{28}$ & 422 & 95 & 517 & -0.657 & $-0.883--0.43$ & \\
Bozeman et al ${ }^{30}$ & 14 & 12 & 26 & 0.264 & $-0.526-1.054$ & \\
& & & & & & \\
Total (fixed effects) & 8,667 & 1,312 & 9,979 & 0.0407 & $-0.017-0.099$ & 0.171 \\
Total (random effects) & 8,667 & 1,312 & 9,979 & -0.176 & $-0.670-0.318$ & 0.484 \\
Test for heterogeneity: $Q=41.8273, P<0.0001$ & & & &
\end{tabular}

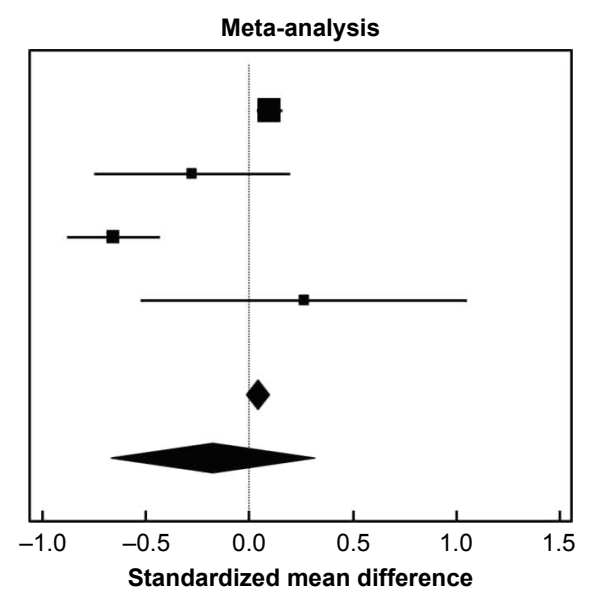

Figure 3 Overall length of stay.

Abbreviations: $\mathrm{Cl}$, confidence interval; NOM, nonoperative management; OM, operative management; SMD, standardized mean difference.

of the mortality rate $(9.1 \%$ vs $17.9 \%$; OR $0.332 ; 95 \% \mathrm{CI}$ 0.155-0.708; $P=0.004$; Figure 9).

When blunt and penetrating high-grade RT data were analyzed separately, we found similar outcomes: mortality in blunt trauma decreased from $8.1 \%$ after OM to $4.1 \%$ after NOM (OR 0.275; 95\% CI 0.0957-0.788; $P=0.016$ ), and in penetrating trauma from $18.1 \%$ after OM to $9.1 \%$ after NOM (OR 0.468; 95\% CI 0.398-0.552; $P<0.001$ ).

Our data demonstrated that hemodynamically stable patients do not always need surgical exploration, because major renal trauma may heal either spontaneously or after minimally invasive procedures. Matthews et al reported spontaneous healing in $87 \%$ of 31 patients affected with a renal injury and urinary extravasation. ${ }^{38}$ Haas et al described a high renal salvage rate using ureteral stents in patients with renal trauma and urinary extravasation. ${ }^{39}$ In a series of 20 patients with either grade 4 or 5 renal trauma who were conservatively treated, Moudouni et al reported six open delayed procedures, whereas the remaining patients healed spontaneously or after ureteral stent positioning. ${ }^{40}$ Altman et al compared two groups of patients affected with grade 5 injuries. $^{7}$ Six were managed conservatively and seven were operated on. The authors affirmed that patients treated conservatively had a lower morbidity rate, with functioning renal parenchyma at follow-up CT scan. ${ }^{7}$

Moreover, our analysis showed a lower LOS of NOM versus $\mathrm{OM}$ and similar morbidity rates of both NOM and OM in patients with BRT or penetrating high-grade renal trauma, suggesting that NOM can be safely undertaken, avoiding laparotomies, kidney resections, and nephrectomies, and allowing hospital cost reduction.

\section{Conclusion}

The results of this meta-analysis showed that not only is NOM the treatment of choice for low-grade RT, but also that it should be considered as the first-line treatment

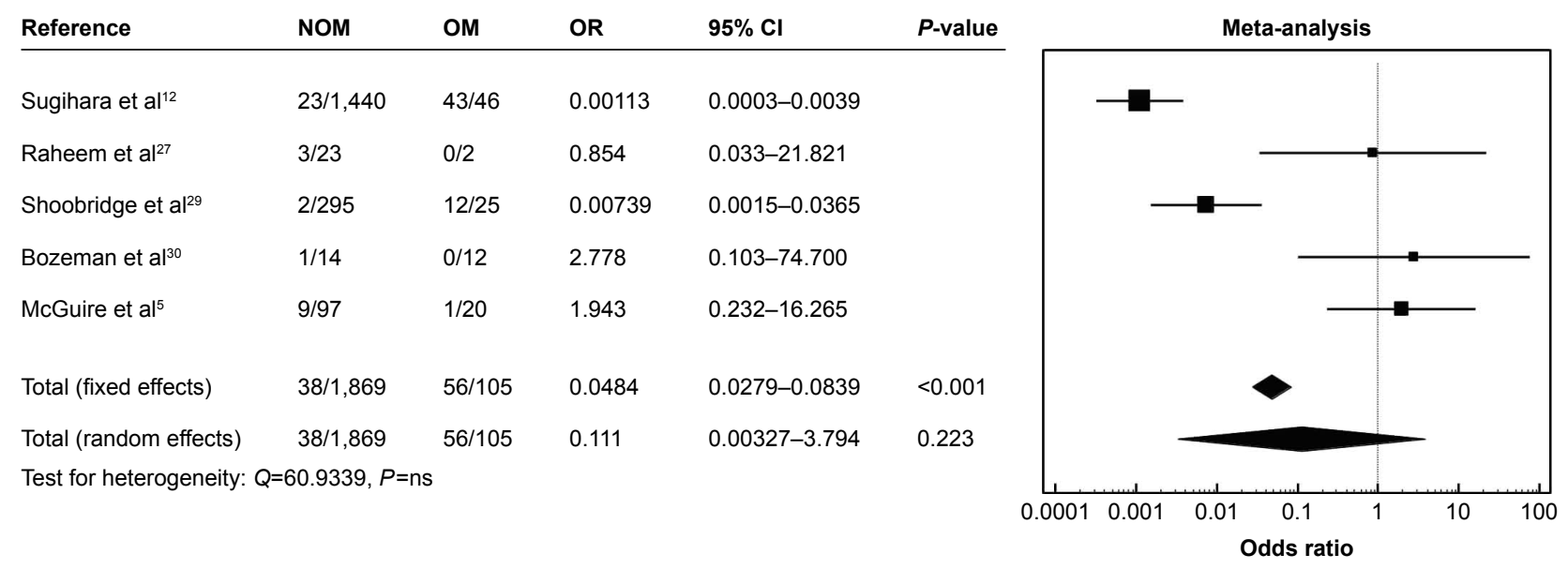

Figure 4 Morbidity for blunt renal trauma.

Abbreviations: $\mathrm{Cl}$, confidence interval; NOM, nonoperative management; ns, not significant; OM, operative management; OR, odds ratio. 


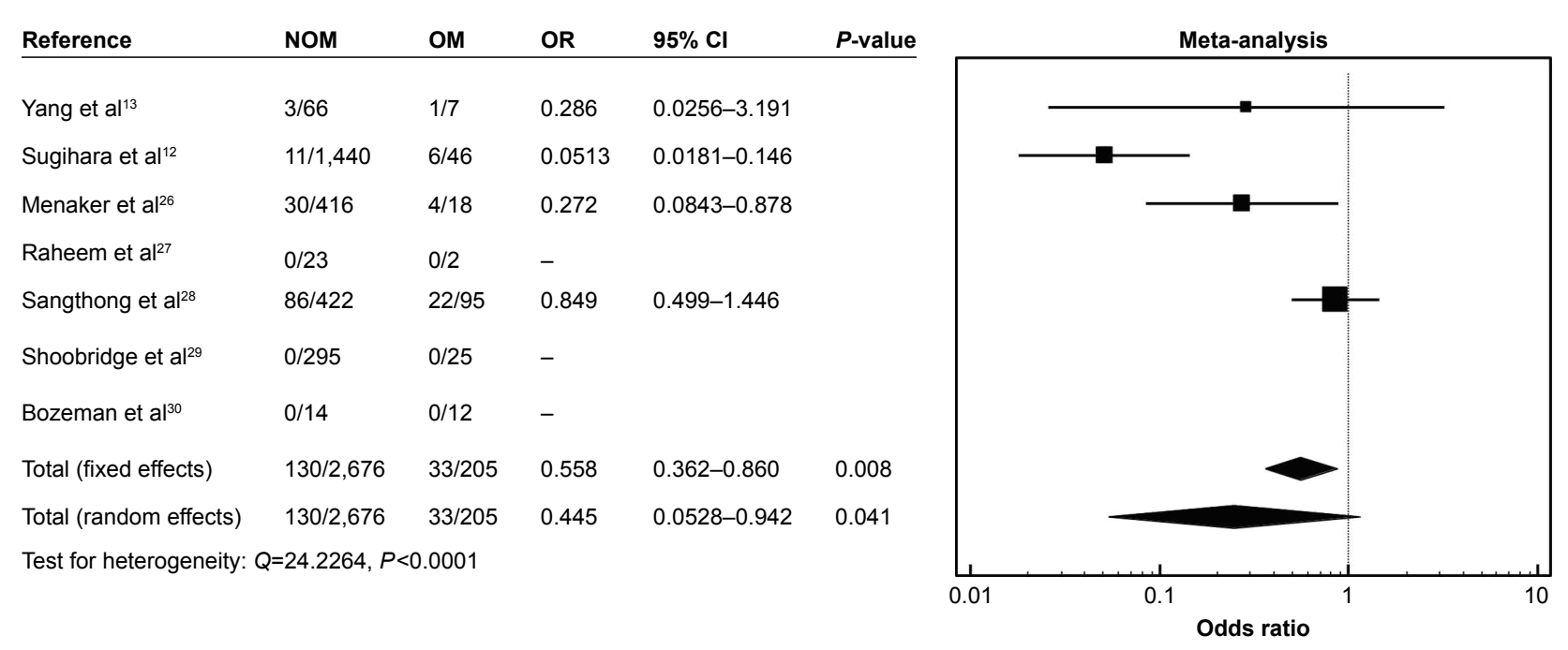

Figure 5 Mortality for blunt renal trauma.

Note: The OR was not calculated when the results at the univariate analysis were not statistically significant: this is represented with "-" and consequently there is no $95 \%$ Cl. Abbreviations: $\mathrm{Cl}$, confidence interval; NOM, nonoperative management; OM, operative management; OR, odds ratio.

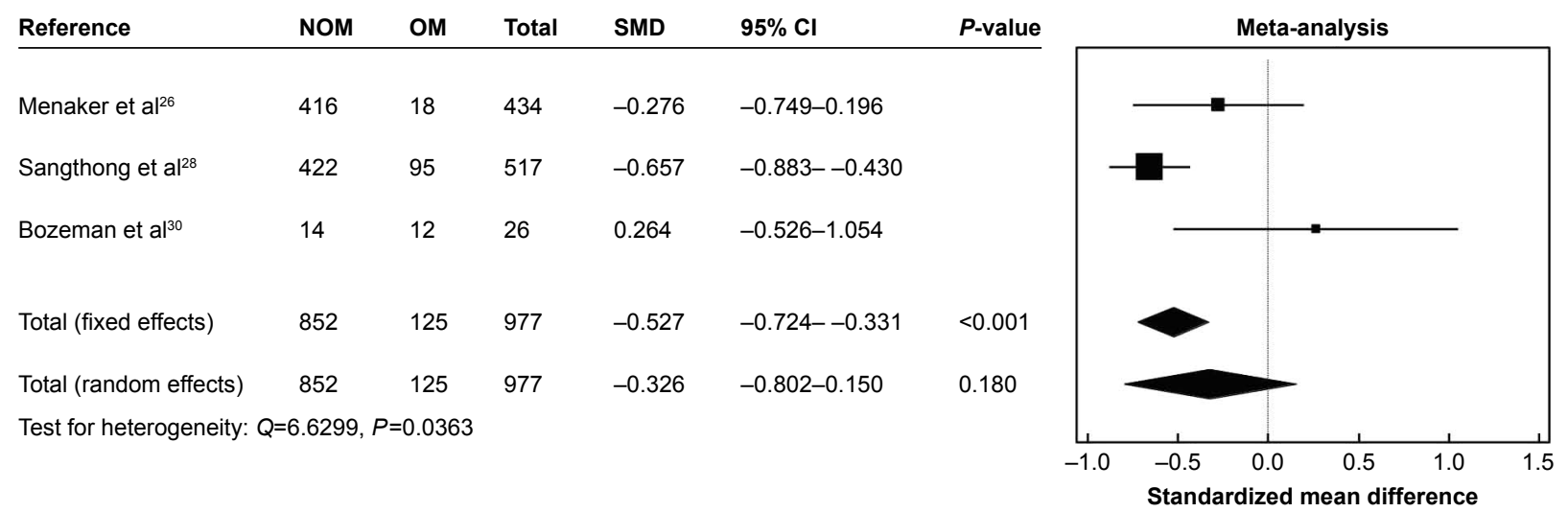

Figure 6 Length of hospital stay for blunt renal trauma.

Abbreviations: $\mathrm{Cl}$, confidence interval; NOM, nonoperative management; OM, operative management; SMD, standardized mean difference.

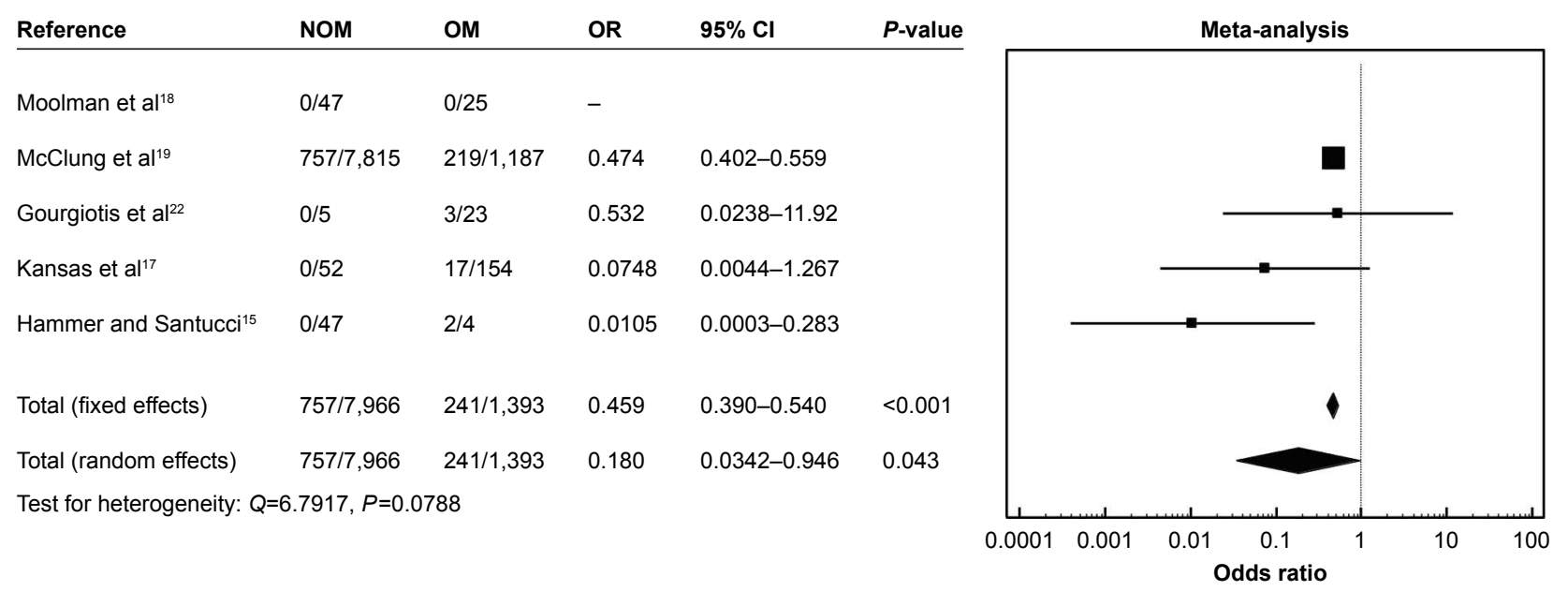

Figure 7 Mortality for penetrating renal trauma.

Note: The OR was not calculated when the results at the univariate analysis were not statistically significant: this is represented with "-" and consequently there is no $95 \% \mathrm{Cl}$. Abbreviations: $\mathrm{Cl}$, confidence interval; NOM, nonoperative management; OM, operative management; OR, odds ratio. 


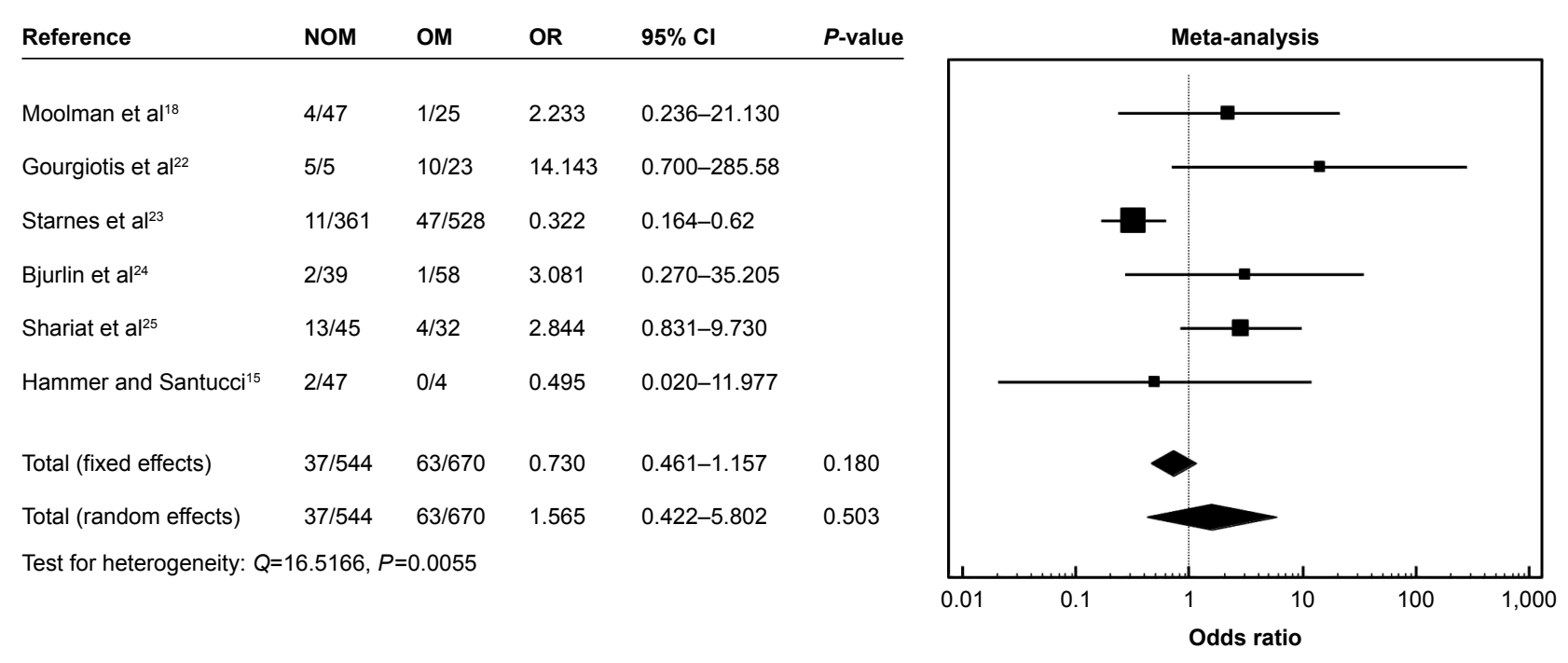

Figure 8 Morbidity for penetrating renal trauma.

Abbreviations: $\mathrm{Cl}$, confidence interval; NOM, nonoperative management; OM, operative management; OR, odds ratio.

\begin{tabular}{|c|c|c|c|c|c|}
\hline Reference & NOM & OM & OR & $95 \% \mathrm{Cl}$ & $P$-value \\
\hline McClung et $\mathrm{al}^{19}$ & $757 / 7,815$ & $219 / 1,187$ & 0.474 & $0.402-0.559$ & \\
\hline Gourgiotis et $\mathrm{al}^{22}$ & $0 / 5$ & $3 / 23$ & 0.532 & $0.0238-11.928$ & \\
\hline Hammer and Santucci ${ }^{15}$ & $0 / 47$ & $2 / 4$ & 0.0105 & $0.00039-0.283$ & \\
\hline Yang et $\mathrm{al}^{13}$ & $3 / 66$ & $1 / 7$ & 0.286 & $0.0256-3.191$ & \\
\hline Menaker et $\mathrm{al}^{26}$ & $30 / 416$ & $4 / 18$ & 0.272 & $0.0843-0.878$ & \\
\hline Shoobridge et $\mathrm{al}^{29}$ & $0 / 295$ & $0 / 25$ & - & & \\
\hline Bozeman et $\mathrm{al}^{30}$ & $0 / 14$ & $0 / 12$ & - & & \\
\hline Total (fixed effects) & $790 / 8,658$ & $229 / 1,276$ & 0.464 & $0.394-0.545$ & $<0.001$ \\
\hline Total (random effects) & $790 / 8,658$ & $229 / 1,276$ & 0.332 & $0.155-0.708$ & 0.004 \\
\hline
\end{tabular}

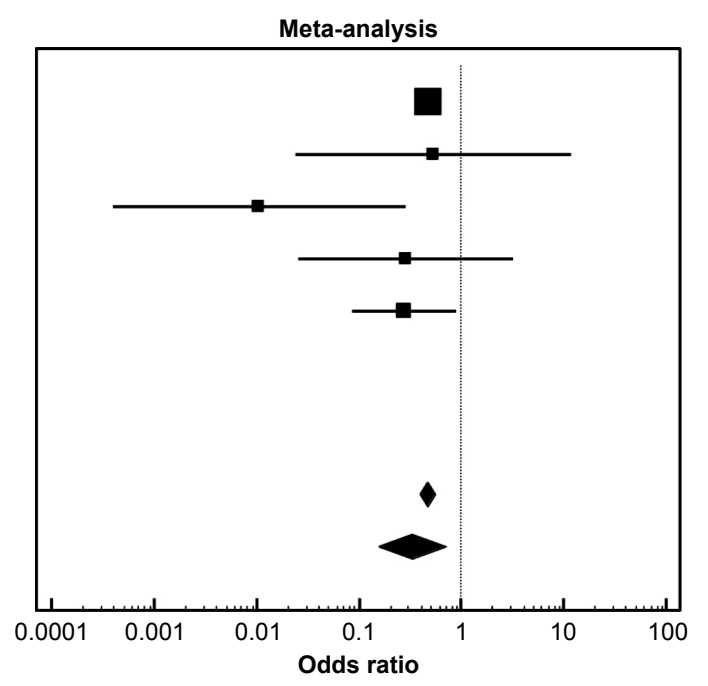

Figure 9 Overall mortality, high-grade renal trauma.

Note: The OR was not calculated when the results at the univariate analysis were not statistically significant: this is represented with "-" and consequently there is no $95 \% \mathrm{Cl}$. Abbreviations: $\mathrm{Cl}$, confidence interval; NOM, nonoperative management; OM, operative management; OR, odds ratio.

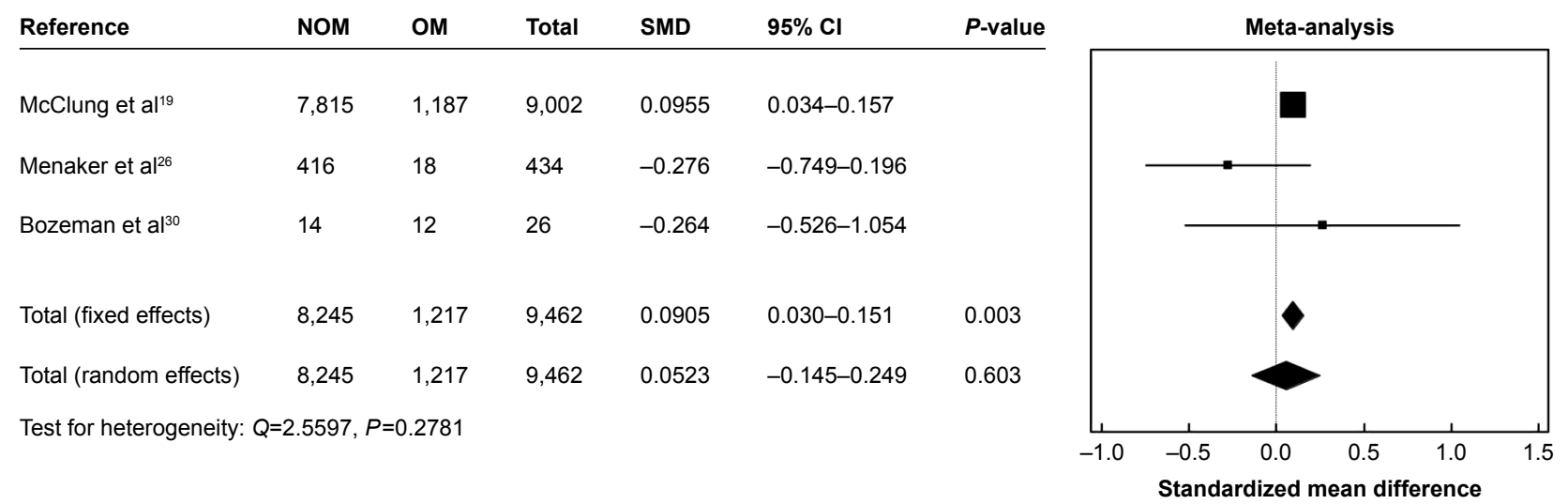

Figure 10 Overall length of stay, high-grade renal trauma.

Abbreviations: $\mathrm{Cl}$, confidence interval; NOM, nonoperative management; OM, operative management; SMD, standardized mean difference. 


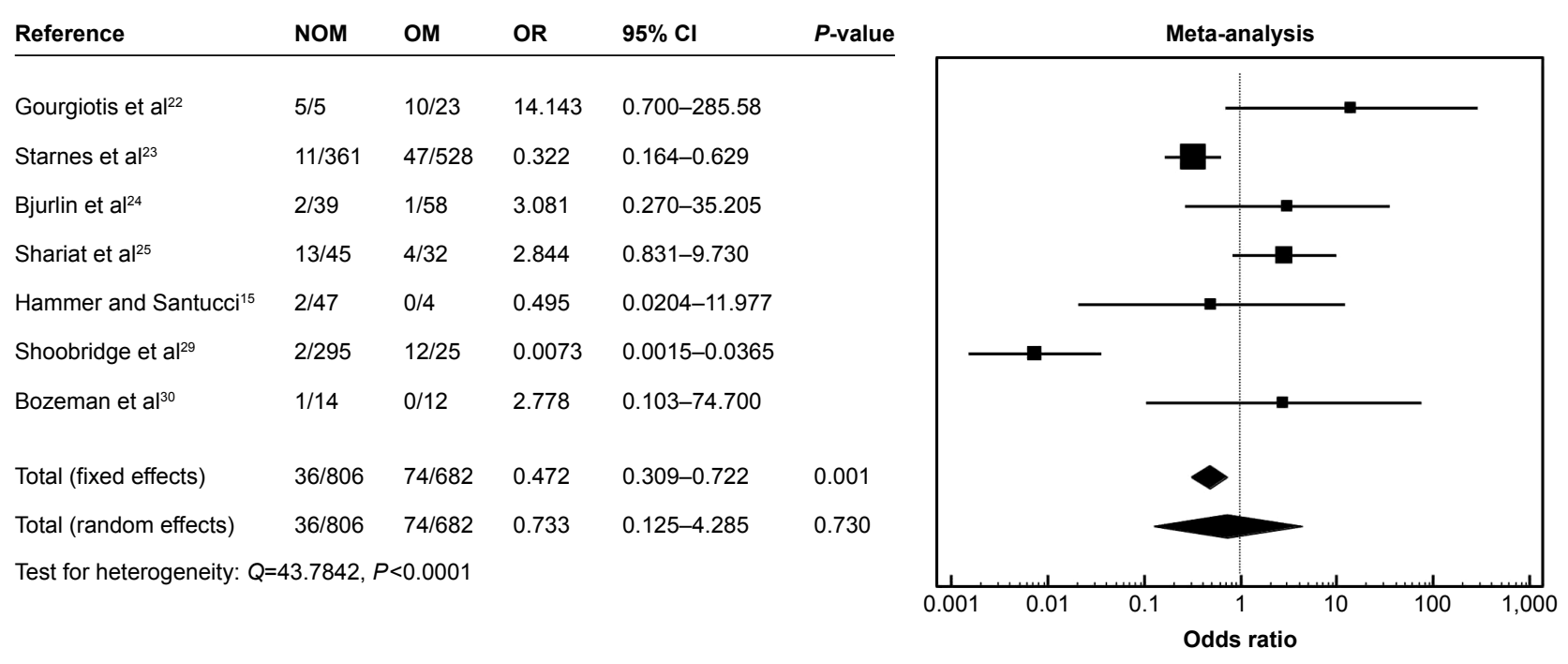

Figure I I Overall morbidity, high-grade renal trauma.

Abbreviations: $\mathrm{Cl}$, confidence interval; NOM, nonoperative management; OM, operative management; OR, odds ratio.

\begin{tabular}{|c|c|c|c|c|c|c|c|c|c|}
\hline Reference & NOM & OM & OR & $95 \% \mathrm{Cl}$ & $P$-value & \multicolumn{4}{|c|}{ Meta-analysis } \\
\hline Yang et $\mathrm{al}^{13}$ & $3 / 66$ & $1 / 7$ & 0.286 & $0.0256-3.191$ & & & & & \\
\hline Menaker et $\mathrm{al}^{26}$ & $30 / 416$ & $4 / 18$ & 0.272 & $0.0843-0.878$ & & & & & \\
\hline Shoobridge et $\mathrm{al}^{29}$ & $0 / 295$ & $0 / 25$ & - & & & & & & \\
\hline Bozeman et al ${ }^{30}$ & $0 / 14$ & $0 / 12$ & - & & & & & & \\
\hline Total (fixed effects) & $33 / 791$ & $5 / 62$ & 0.275 & $0.0957-0.788$ & 0.016 & & & & \\
\hline Total (random effects) & $33 / 791$ & $5 / 62$ & 0.275 & $0.0957-0.788$ & 0.016 & & & & \\
\hline \multicolumn{10}{|c|}{ Test for heterogeneity: $Q=0.001288, P=0.9714$} \\
\hline & & & & & & 0.01 & 0.1 & 1 & 10 \\
\hline
\end{tabular}

Figure 12 Mortality in high-grade blunt trauma.

Note: The OR was not calculated when the results at the univariate analysis were not statistically significant: this is represented with "-" and consequently there is no $95 \% \mathrm{Cl}$. Abbreviations: $\mathrm{Cl}$, confidence interval; NOM, nonoperative management; OM, operative management; OR, odds ratio.

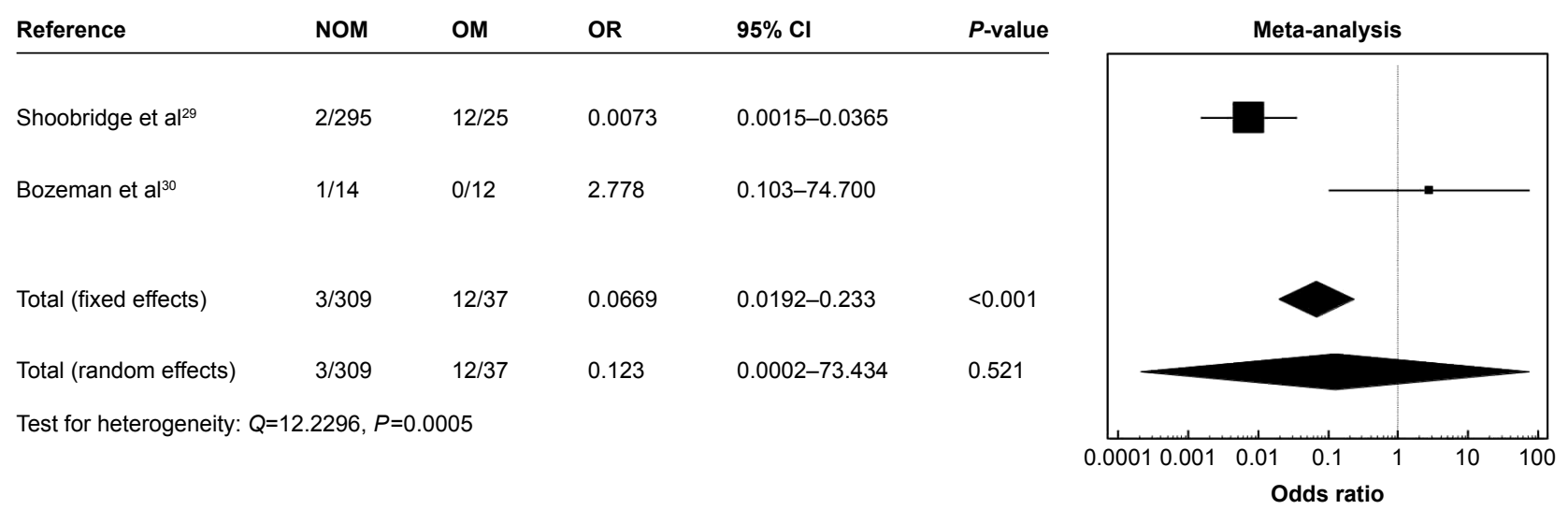

Figure 13 Morbidity in high-grade blunt trauma.

Abbreviations: $\mathrm{Cl}$, confidence interval; NOM, nonoperative management; OM, operative management; OR, odds ratio. 


\begin{tabular}{lcccccc}
\hline Reference & NOM & OM & Total & SMD & 95\% CI & $P$-value \\
\hline Menaker et al ${ }^{26}$ & 416 & 18 & 434 & -0.276 & $-0.749-0.196$ \\
Bozeman et al ${ }^{30}$ & 14 & 12 & 26 & 0.264 & $-0.526-1.054$ & 0.545 \\
Total (fixed effects) & 430 & 30 & 460 & -0.123 & $-0.524-0.277$ & \\
Total (random effects) & 430 & 30 & 460 & -0.0880 & $-0.594-0.418$ & \\
Test for heterogeneity: $Q=1.4309, P=0.2316$ & & & &
\end{tabular}

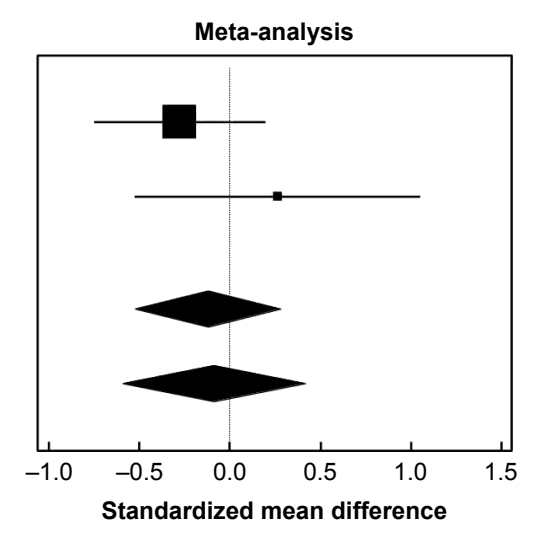

Figure 14 Length of stay in high-grade blunt trauma.

Abbreviations: $\mathrm{Cl}$, confidence interval; NOM, nonoperative management; OM, operative management; SMD, standardized mean difference.

\begin{tabular}{llllll} 
Reference & NOM & OM & OR & 95\% Cl & $P$-value \\
\hline Moolman et al ${ }^{18}$ & $0 / 47$ & $0 / 25$ & - & \\
McClung et al ${ }^{19}$ & $757 / 7,815$ & $219 / 1,187$ & 0.474 & $0.402-0.559$ \\
Gourgiotis et al ${ }^{22}$ & $0 / 5$ & $3 / 23$ & 0.532 & $0.0238-11.928$ \\
Hammer and Santucci ${ }^{15}$ & $0 / 47$ & $2 / 4$ & 0.0105 & $0.0003-0.283$ & \\
& & & & & \\
Total (fixed effects) & $757 / 7,914$ & $224 / 1,239$ & 0.468 & $0.398-0.552$ & $<0.001$ \\
Total (random effects) & $757 / 7,914$ & $224 / 1,239$ & 0.205 & $0.0259-1.628$ & 0.134 \\
Test for heterogeneity: $Q=5.1336, P=0.0768$ & &
\end{tabular}

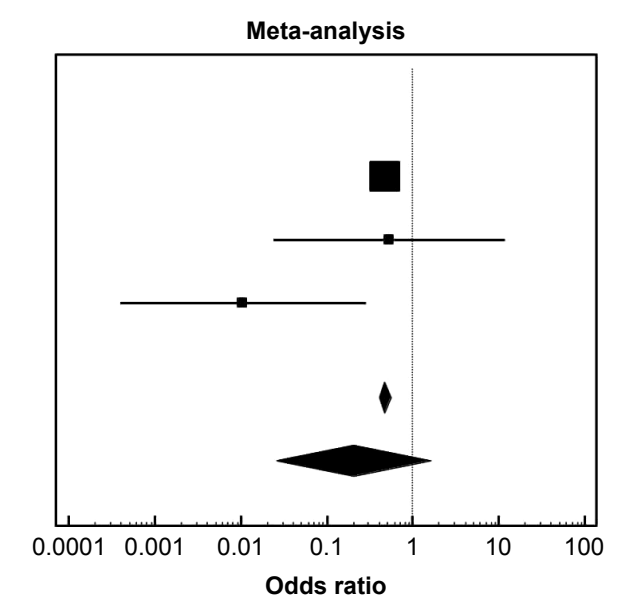

Figure 15 Mortality in high-grade penetrating trauma.

Note: The OR was not calculated when the results at the univariate analysis were not statistically significant: this is represented with "-" and consequently there is no $95 \% \mathrm{Cl}$. Abbreviations: $\mathrm{Cl}$, confidence interval; NOM, nonoperative management; OM, operative management; OR, odds ratio.

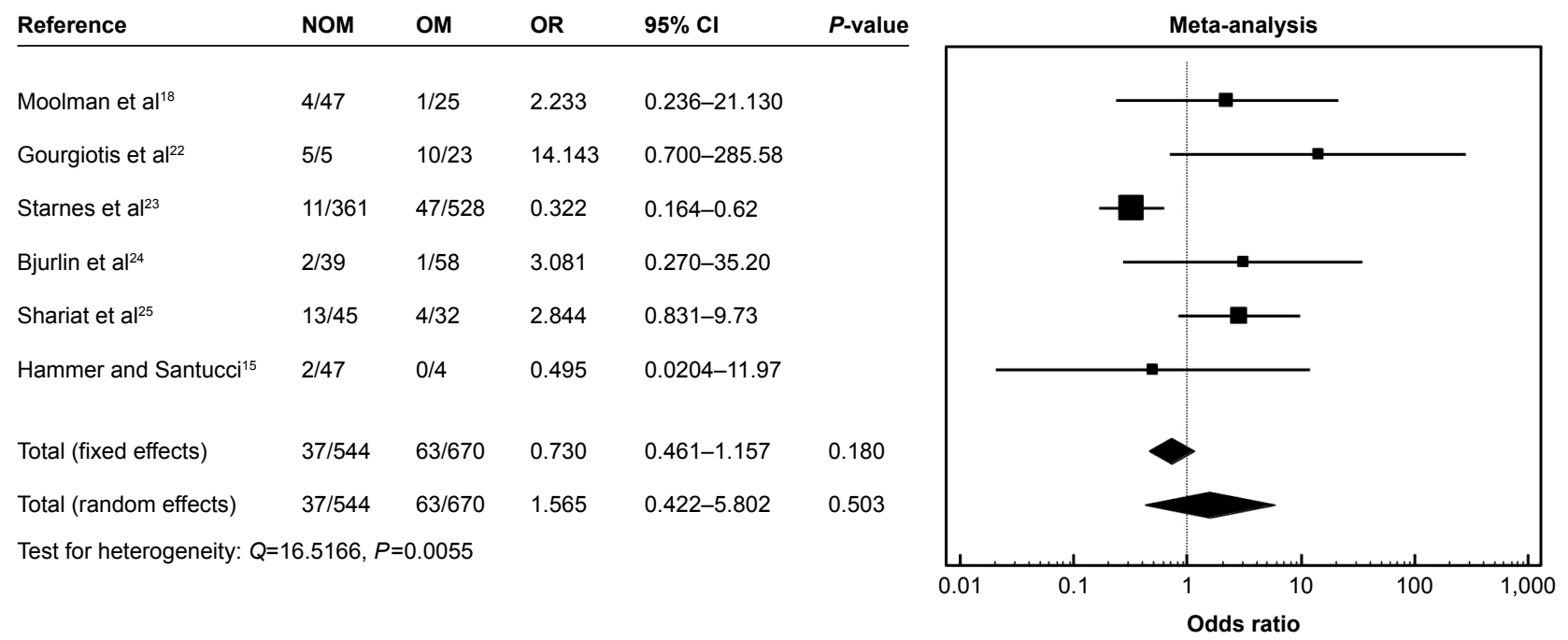

Figure 16 Morbidity in high-grade penetrating trauma.

Abbreviations: $\mathrm{Cl}$, confidence interval; NOM, nonoperative management; OM, operative management; OR, odds ratio. 
even for high-grade blunt or penetrating RT, because it is associated to lower mortality rates and LOS, and similar morbidity rates.

\section{Disclosure}

The authors certify that they have no affiliations with or involvement in any organization or entity with any financial interest in the subject matter discussed in this manuscript and report no conflicts of interest in this work.

\section{References}

1. Kuan JK, Wright JL, Nathens AB, Rivara FP, Wessells H; American Association for the Surgery of Trauma. American Association for the Surgery of Trauma Organ Injury Scale for kidney injuries predicts nephrectomy, dialysis, and death in patients with blunt injury and nephrectomy for penetrating injuries. J Trauma. 2006;60(2):351-356.

2. Shariat SF, Trinh QD, Morey AF, et al. Development of a highly accurate nomogram for prediction of the need for exploration in patients with renal trauma. J Trauma. 2008;64(6):1451-1458.

3. Santucci RA, Wessells H, Bartsch G, et al. Evaluation and management of renal injuries: consensus statement of the renal trauma subcommittee. BJU Int. 2004;93(7):937-954.

4. Hommes M, Navsaria PH, Schipper IB, Krige JE, Kahn D, Nicol AJ. Management of blunt liver trauma in 134 severely injured patients. Injury. 2015;46(5):837-842.

5. McGuire J, Bultitude MF, Davis P, Koukounaras J, Royce PL, Corcoran NM. Predictors of outcome for blunt high grade renal injury treated with conservative intent. J Urol. 2011;185(1):187-191.

6. McAninch JW, Federle MP. Evaluation of renal injuries with computerized tomography. J Urol. 1982;128(3):456-460.

7. Altman AL, Haas C, Dinchman KH, Spirnak JP. Selective nonoperative management of blunt grade 5 renal injury. J Urol. 2000;164(1):27-30; discussion 30-31.

8. Moudouni SM, Hadj Slimen M, Manunta A, et al. Management of major blunt renal lacerations: is a nonoperative approach indicated? Eur Urol. 2001;40(4):409-414.

9. Hagiwara A, Sakaki S, Goto H, et al. The role of interventional radiology in the management of blunt renal injury: a practical protocol. J Trauma. 2001;51(3):526-531.

10. Husmann DA, Gilling PJ, Perry MO, Morris JS, Boone TB. Major renal lacerations with a devitalized fragment following blunt abdominal trauma: a comparison between nonoperative (expectant) versus surgical management. J Urol. 1993;150(6):1774-1777.

11. Moher D, Liberati A, Tetzlaff J, Altman DG; PRISMA Group. Preferred reporting items for systematic reviews and meta-analyses: the PRISMA statement. PLoS Med. 2009;6(7):e1000097.

12. Sugihara T, Yasunaga H, Horiguchi H, et al. Management trends, angioembolization performance and multiorgan injury indicators of renal trauma from Japanese administrative claims database. Int J Urol. 2012;19(6):559-563; author reply 564.

13. Yang CS, Chen IC, Wang CY, Liu CC, Shih HC, Huang MS. Predictive indications of operation and mortality following renal trauma. $J$ Chin Med Assoc. 2012;75(1):21-24.

14. Sahin H, Akay AF, Yilmaz G, Taçyildiz IH, Bircan MK. Retrospective analysis of 135 renal trauma cases. Int J Urol. 2004;11(5):332-336.

15. Hammer CC, Santucci RA. Effect of an institutional policy of nonoperative treatment of grades I to IV renal injuries. J Urol. 2003;169(5): $1751-1753$.

16. Buckley JC, McAninch JW. Selective management of isolated and nonisolated grade IV renal injuries. J Urol. 2006;176(6 Pt 1):2498-2502; discussion 2502.

17. Kansas BT, Eddy MJ, Mydlo JH, Uzzo RG. Incidence and management of penetrating renal trauma in patients with multiorgan injury: extended experience at an inner city trauma center. J Urol. 2004; 172(4 Pt 1):1355-1360.
18. Moolman C, Navsaria PH, Lazarus J, Pontin A, Nicol AJ. Nonoperative management of penetrating kidney injuries: a prospective audit. $J$ Urol. 2012;188(1):169-173.

19. McClung CD, Hotaling JM, Wang J, Wessells H, Voelzke BB. Contemporary trends in the immediate surgical management of renal trauma using a national database. J Trauma Acute Care Surg. 2013;75(4): 602-606.

20. Aragona F, Pepe P, Patanè D, Malfa P, D'Arrigo L, Pennisi M. Management of severe blunt renal trauma in adult patients: a 10-year retrospective review from an emergency hospital. BJU Int. 2012;110(5): 744-748.

21. van der Vlies CH, Olthof DC, van Delden OM, et al. Management of blunt renal injury in a level 1 trauma centre in view of the European guidelines. Injury. 2012;43(11):1816-1820.

22. Gourgiotis S, Germanos S, Dimopoulos N, Vougas V, Anastasiou T, Baratsis S. Renal injury: 5-year experience and literature review. Urol Int. 2006;77(2):97-103.

23. Starnes M, Demetriades D, Hadjizacharia P, Inaba K, Best C, Chan L. Complications following renal trauma. Arch Surg. 2010;145(4): 377-381; discussion 381-382.

24. Bjurlin MA, Jeng EI, Goble SM, Doherty JC, Merlotti GJ. Comparison of nonoperative management with renorrhaphy and nephrectomy in penetrating renal injuries. J Trauma. 2011;71(3):554-558.

25. Shariat SF, Jenkins A, Roehrborn CG, Karam JA, Stage KH, Karakiewicz PI. Features and outcomes of patients with grade IV renal injury. BJU Int. 2008;102(6):728-733; discussion 733.

26. Menaker J, Joseph B, Stein DM, Scalea TM. Angiointervention: high rates of failure following blunt renal injuries. World J Surg. 2011; 35(3):520-527.

27. Raheem O, Floyd MS Jr, Casey RG, et al. Renal trauma in the west of Ireland - a regional review. ScientificWorldJournal. 2009;9:137-143.

28. Sangthong B, Demetriades D, Martin M, et al. Management and hospital outcomes of blunt renal artery injuries: analysis of 517 patients from the National Trauma Data Bank. J Am Coll Surg. 2006;203(5): 612-617.

29. Shoobridge JJ, Bultitude MF, Koukounaras J, Martin KE, Royce PL, Corcoran NM. A 9-year experience of renal injury at an Australian level 1 trauma centre. BJU Int. 2013;112(Suppl 2):53-60.

30. Bozeman C, Carver B, Zabari G, Caldito G, Venable D. Selective operative management of major blunt renal trauma. J Trauma. 2004;57(2): 305-309.

31. Wells GA, Shea B, O'Connell D, et al. The Newcastle-Ottawa Scale (NOS) for assessing the quality of non randomized studies in meta-analyses. Ottawa, ON: Ottawa Hospital Research Institute. Available from: http://www.ohri.ca/programs/clinical_epidemiology/ oxford.htm. Accessed December 15, 2016.

32. Wessells H, McAninch JW, Meyer A, Bruce J. Criteria for nonoperative treatment of significant penetrating renal lacerations. J Urol. 1997; 157(1):24-27.

33. Velmahos GC, Demetriades D, Cornwell EE 3rd, et al. Selective management of renal gunshot wounds. Br J Surg. 1998;85(8):1121-1124.

34. Demetriades D, Hadjizacharia P, Constantinou C, et al. Selective nonoperative management of penetrating abdominal solid organ injuries. Ann Surg. 2006;244(4):620-628.

35. Christmas AB, Wilson AK, Manning B, et al. Selective management of blunt hepatic injuries including nonoperative management is a safe and effective strategy. Surgery. 2005;138(4):606-610; discussion 610-611.

36. Gourgiotis S, Vougas V, Germanos S, et al. Operative and nonoperative management of blunt hepatic trauma in adults: a single-center report. J Hepatobiliary Pancreat Surg. 2007;14(4):387-391.

37. Scarborough JE, Ingraham AM, Liepert AE, Jung HS, O'Rourke AP, Agarwal SK. Nonoperative management is as effective as immediate splenectomy for adult patients with high-grade blunt splenic injury. J Am Coll Surg. 2016;223(2):249-258.

38. Matthews LA, Smith EM, Spirnak JP. Nonoperative treatment of major blunt renal lacerations with urinary extravasation. J Urol. 1997; 157(6):2056-2058. 
39. Haas CA, Reigle MD, Selzman AA, Elder JS, Spirnak JP. Use of ureteral stents in the management of major renal trauma with urinary extravasation: is there a role? J Endourol. 1998;12(6):545-549.
40. Moudouni SM, Patard JJ, Manunta A, Guiraud P, Guille F, Lobel B. A conservative approach to major blunt renal lacerations with urinary extravasation and devitalized renal segments. BJU Int. 2001;87(4):290-294.

\section{Publish your work in this journal}

Therapeutics and Clinical Risk Management is an international, peerreviewed journal of clinical therapeutics and risk management, focusing on concise rapid reporting of clinical studies in all therapeutic areas, outcomes, safety, and programs for the effective, safe, and sustained use of medicines. This journal is indexed on PubMed Central, CAS,
EMBase, Scopus and the Elsevier Bibliographic databases. The manuscript management system is completely online and includes a very quick and fair peer-review system, which is all easy to use. Visit http://www.dovepress.com/testimonials.php to read real quotes from published authors. 